\title{
Should the management of radiation therapy for breast cancer be standardized? Results of a survey on current French practices in breast radiotherapy
}

\author{
Martin Schmitt, Jordan Eber, Delphine Antoni, Georges Noel \\ Radiotherapy Department, Institut du Cancer, Strasbourg, Europe, France
}

\begin{abstract}
Background: Breast cancer is the most frequent cancer in women in France. Its management has evolved considerably in recent years with a focus on reducing iatrogenic toxicity. The radiotherapy indications are validated in multidisciplinary consultation meetings; however, questions remain outstanding, particularly regarding hypofractionated radiotherapy, partial breast irradiation, and irradiation of the internal mammary chain and axillary lymph node area.

Materials and methods: An online survey was sent to 47 heads of radiotherapy departments in France. The survey consisted of 22 questions concerning indications for irradiation of the supraclavicular, internal mammary and axillary lymph node areas; irradiation techniques and modalities; prescribed doses; and fractionation.

Results: Twenty-four out of 47 centers responded (response rate of 51\%). This survey demonstrated a wide variation in the prescribed dose regimen, monoisocentric radiotherapy, and indications of irradiation of the lymph node areas.

Conclusion: This survey provides insight into the current radiotherapy practice for breast cancer in France. It shows the need to standardize practices.
\end{abstract}

Key words: breast cancer; clinical practice; radiotherapy; survey

Rep Pract Oncol Radiother 2021;26(5):814-826

\section{Introduction}

Breast cancer is the most frequent cancer in women in France [1]. Management has considerably evolved in recent years with the introduction of advanced irradiation techniques and schedules such as intensity modulated radiotherapy (IMRT), hypofractionated radiotherapy (HF-RT) and partial irradiation $[2,3]$. On the surgical side, the sentinel node ( $\mathrm{SN}$ ) procedure has become increasingly important to the detriment of systematic axillary lymph node dissection (ALND), and recently, the AMAROS trial showed that in patients with stage
T1-2 breast cancer with one to two lymph node metastases, radiotherapy could substitute for ALND [4]. However, if the indication of radiotherapy is validated in a multidisciplinary consultation meeting (MTM), the technique and the definition of target volumes are frequently at the discretion of the radiation oncologist or depend on department protocols. A guide to external radiotherapy procedures, published in 2007 in its first version and in 2016 in its second version, aimed to optimize, harmonize and homogenize national practices. In 2021, one hundred and seventy-five centers were performing radiotherapy in France, and thirty-four 


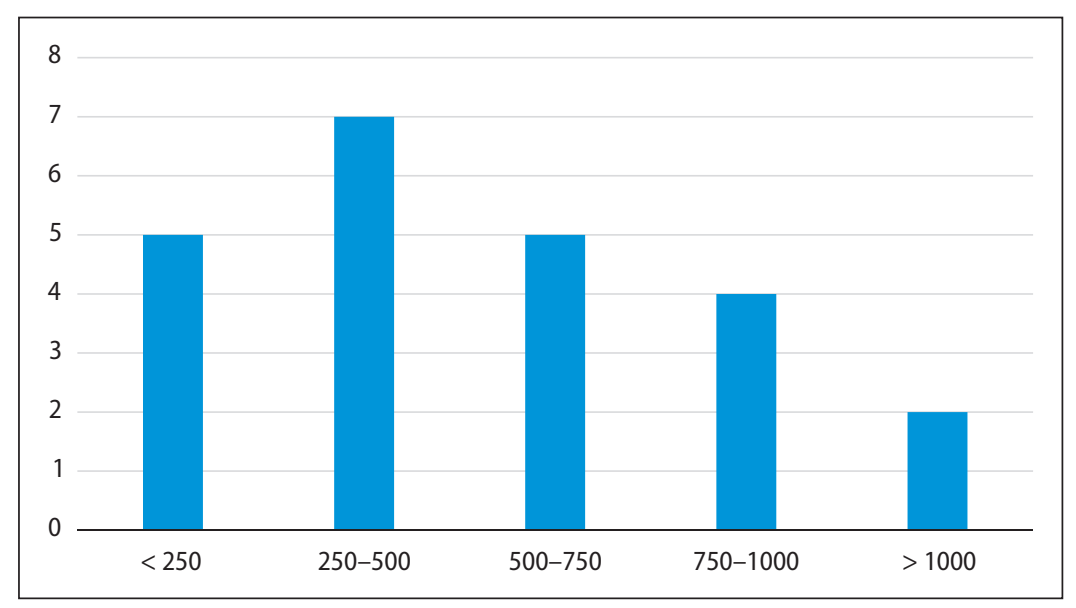

Figure 1. Number of breast cancers treated per year. The $\mathrm{X}$-axis shows the number of patients treated per year, and the $\mathrm{Y}$-axis shows the number of centers

were authorized to perform brachytherapy. There are 25 Comprehensive cancer centers and 25 University centers. Currently, each radiotherapy center treats at least 600 patients per year. The purpose of this national survey sent to French Comprehensive cancer centers and university centers was to look for and describe potential heterogeneities in current practices.

\section{Materials and methods}

All French Comprehensive cancer centers as well as university radiotherapy centers were surveyed, except 3 because of a refusal to communicate their email addresses. The survey was carried out on the www.survio.com website, and a link was provided to each of the 47 heads of radiotherapy departments in France (Supplementary File - Appendix A). Anonymous responses were recorded from April 2020 to July 2020. The survey included 22 questions concerning irradiation indications of the supraclavicular, internal mammary and axillary lymph node areas; irradiation techniques and modalities; prescription doses; and fractionation.

\section{Results and Discussion}

Question 1: Seventy-one percent (17/24) of respondents considered themselves to be experts in breast cancers.

Questions 2 and 3: Of the 47 centers, 23 responded to the survey. The number of cases treated per year in each center is shown in Figure 1. Cases were systematically presented at radiotherapy technical committees in ten centers, only for cases considered difficult in seven centers and never in six others.

In comparison, in the Nodal Radiotherapy (NORA) survey, $82 \%$ of the centers validated the volumes and modalities of irradiation at technical meetings [5]. This decrease in the requirement for technical meetings could be partly explained by the publication of recent recommendations, such as the ESTRO (European Society for Radiotherapy and Oncology) recommendations for the delineation of target volumes and the ASTRO (American Society for Radiotherapy and Oncology) guidelines that have made breast irradiation a well-supervised practice $[6,7]$.

Questions 4 and 5: Concerning irradiation techniques, all of the questioned centers carry out breast and chest wall irradiation in three-dimensional radiotherapy (3DRT). In the case of mammary or chest wall irradiation in three-dimensional radiotherapy, $30 \%$ of the centers systematically used a monoisocentric technique. However, the majority of the centers reserved this technique for particular cases or never used it (Fig. 2).

Monoisocentric 3DRT was first described for breast cancer in 1984 [8]. Better dose homogeneity in the junction zones, better sparing of organs at risk and better reproducibility compared to a technique with two isocenters have been demonstrated [9-11]. Despite these advantages, its use seems low in France. Regarding this observation, we hypoth- 




Figure 2. Use of the monoisocentric technique in three-dimensional radiotherapy

esize that the following reasons may account for its low use: i) difficulty in finding an appropriate dose calculation reference point [10], ii) tangential field length limited to $20 \mathrm{~cm}$ due to half-beam blocking [12], iii) lack of randomized trials or iv) technical limitations due to the treatment machines in place.

Question 6: After total mastectomy, the majority of participants (56.5\%) did not have treatment with electron beams, and none had systematic irradiation of the chest wall with electron beams.

Theoretically, electron-beam chest wall irradiation has an advantage over photon-beam chest wall irradiation because of the rapidly decreased depth-dose curve. In the case of adjuvant irradiation after total mastectomy, several studies have shown the possibility of carrying out irradiation with an electron beam of variable energy according to the thickness of the thoracic wall to be treated [13-15]. It has already been shown that this technique yields locoregional control, disease-free survival, and overall survival rates similar to those of standard photon beam radiotherapy $[13,14$, 16]. However, because of variations in patients' chest wall thickness, CT-based planning is necessary for accurate electron beam energy selection to ensure optimal target coverage while minimizing normal tissue dose [17]; plus, the source-surface distance would vary dramatically across the field, which would lead to excessive dose heterogeneity in the target tissues, a situation that would be enhanced in selected patients with greater chest wall curvature.

Question 7: Concerning IMRT, 74\% of the centers used this technique in cases of pectus excavatum and $61 \%$ used bilateral whole breast irradiation (WBI) or bilateral wall chest irradiation associated with regional nodal areas. Five centers never treated breast cancer with IMRT, and only one center systematically treated breast cancer with IMRT (Fig. 3).

While 3DRT remains the standard in adjuvant breast cancer, several studies have shown the increase in the use of IMRT $(18,19)$. According to expert agreement, IMRT would be indicated in cases of complex anatomy, bilateral breast irradiation, breast prosthesis and situations where no compromise should be made in the predicted target volume (20). Several dosimetric studies have shown a significant difference in the homogeneity of the delivered dose and in the sparing of organs at risk in favor of IMRT [21-23]. However, these indications of IMRT are discussed, and the distribution of low doses in healthy tissues has been scarcely documented [24] but seems to be more important than that delivered by 3DRT $[21,25]$. This raises the question of the risk of potential radiation-induced second cancer in patients whose life expectancy may be long [26-28].

Questions 8 and 9: None of the centers performed brachytherapy boost. Boost by external irradiation with photons is performed by $91 \%$ of the centers, and the use of electrons is less frequent and was used in only $61 \%$ of the centers. Sequential boost was performed by $96 \%$ of the centers.

The lack of use of brachytherapy for boost may be due to the lack of access to the technique. Only 56 centers were practicing brachytherapy in France in 2013, a number that has been declining since 2008. This is probably due to the disappearance of iridium-192 wires and inadequate funding. Bartelink et al. showed a significant decrease in the local recurrence rate $(\mathrm{p}<0.0001)$ when the boost was irradiated either by electrons or photons with tangential beams or by brachytherapy with an iridium-192 implant. However, the authors showed a significantly higher rate of severe skin fibrosis at 10 years in the group that received a boost $(\mathrm{p}<0.0001)$ [29].

The EORTC trial number NCT02295033 showed a significant reduction in the 20 -year cumulative 


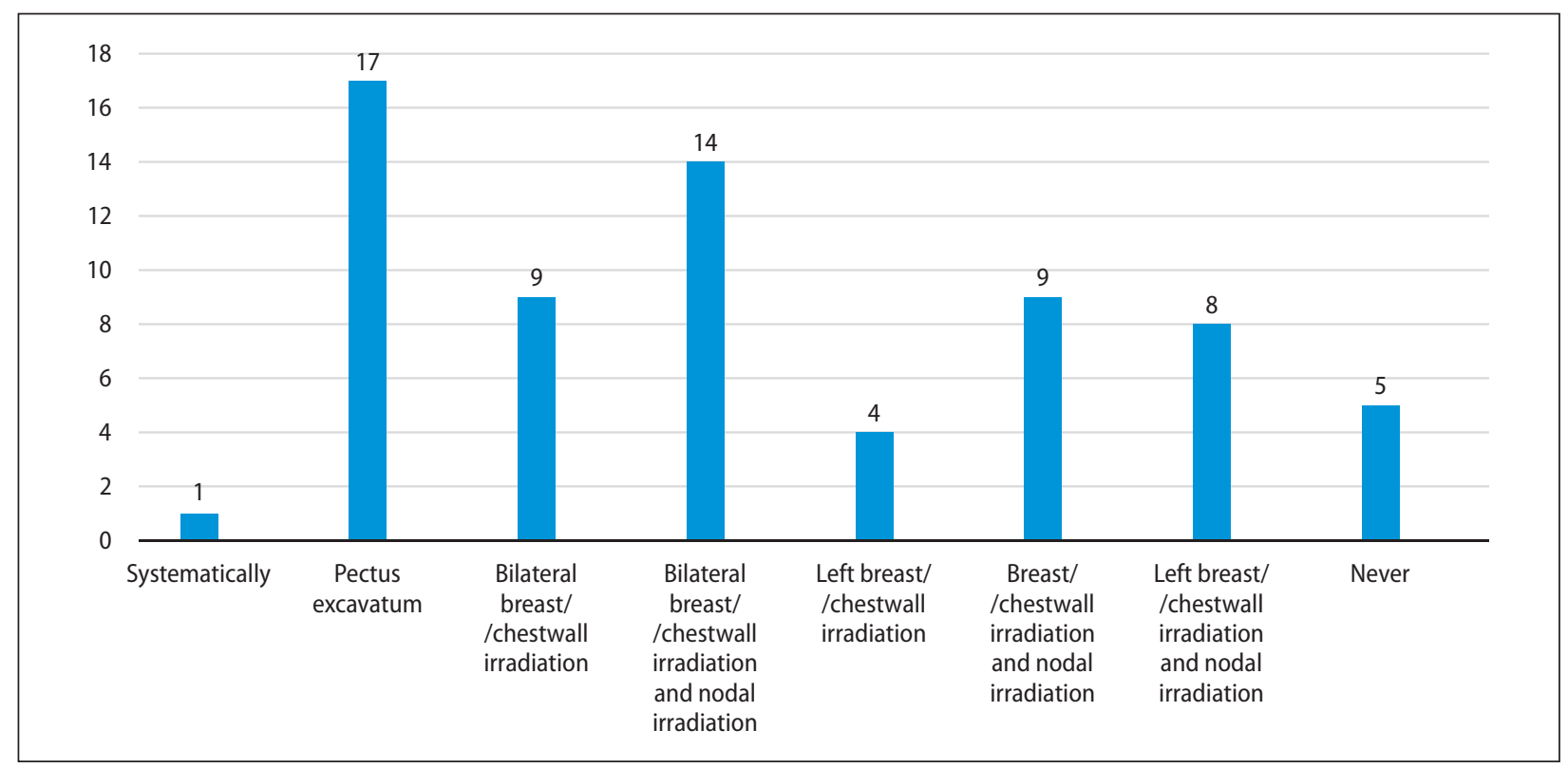

Figure 3. Indication for intensity modulation radiotherapy

incidence of homolateral intramammary recurrence from $31 \%$ (95\% CI: $22-39 \%$ ) to $15 \%$ (95\% CI: $8-21 \%$ ) when a boost was performed in high-risk patients [30].

A retrospective analysis was conducted to assess whether the choice of a boost technique could influence the local recurrence rate. The authors showed that at 13.1 years of median follow-up, there were no significant differences difference in the local recurrence rate between electron beam, brachytherapy or photon beam [31]. A randomized trial showed that at 36 months of follow-up, there were no significant differences in the overall global cosmetic scores between the implant boost group and the photon/electron boost group; telangiectasia was more severe, and the breast retraction assessment value was greater in the implant group [32].

Since the development of IMRT, simultaneously integrated boost (SIB) is technically easy to perform. Renoult et al. demonstrated in a retrospective study that the 5-year overall, no recurrence and local no recurrence survival rates were $98.2 \%, 100 \%$ and $100 \%$, respectively, in patients treated for stage T1-T2N0 breast cancer by conservative surgery and IMRT at a dose of 50 Gy with a concomitant boost of 10 Gy in 10 fractions of 1 Gy [33]. The SIB allows for a reduction in the treatment time [34]. There was no evidence of increased long-term toxicity with increasing dose per fraction $[35,36]$. The IMRT-MC2 trial (NCT01322854) is a prospective phase III, multicenter, randomized trial comparing IMRT with SIB and 3DRT irradiation with sequential boost. The main objective is the evaluation of cosmetic results at 6 weeks and 2 years and the local recurrence rate at 2 and 5 years after the end of irradiation.

Questions 10 and 11: Except for inclusions in clinical trials, three centers (13\%) performed partial breast irradiation (PBI) according to indications. External beam irradiation was the technique used in the majority of cases; two centers used it, while one center also used brachytherapy, and another performed intraoperative irradiation.

The survey published by Dundas et al. showed similar results, with $11 \%$ of the radiotherapy centers proposing partial radiotherapy [37]. The justification for postoperative PBI is based on the low recurrence rate in the remaining gland after external irradiation and the reduction in irradiated volumes with a consequent reduction in side effects. Indeed, Bartelink et al. noted 5 to $7 \%$ grade 3 mammary fibrosis after total breast irradiation by opposite tangential beams, of which the two main risk factors were the breast volume irradiated and the total irradiation dose [29]. In addition, it should be noted that 80 to $90 \%$ of local relapses occurred at the lumpectomy site [38]. Two recent randomized phase III trials compared postoperative external PBI with WBI $[39,40]$. Livi et al. 
showed a noninferiority of PBI with IMRT compared to WBI with a 5-year recurrence rate in the homolateral breast of less than or equal to $1.5 \%$ in both groups [39]. Coles et al. randomized 2018 patients into three groups (two groups receiving external WBI at a dose of 40 Gy in 15 fractions and 36 Gy in 15 fractions and one group receiving PBI at a dose of 40 Gy in 15 fractions). Patients in both groups were treated with IMRT. It was shown that PBI was not inferior to WBI, with 5-year local recurrence rates equal to $1 \%$ in both arms [40]. Indications for PBI are currently reserved for selected patients with a very low risk of tumor recurrence [41]. The randomized trial of the Groupe Européen de Curiethérapie and European Society for Radiotherapy and Oncology (GEC ESTRO) showed that interstitial brachytherapy was noninferior to WBI, with 5-year local recurrence rates of less than 1.5\% in both arms [42].

Irradiation can be performed intraoperatively. To date, two randomized trials have been published: ELIOT and TARGIT-A. The authors of both trials showed a significant increase in local recurrences in the arms with intraoperative radiotherapy $[2,3]$. Partial irradiation therefore remains marginal in France and is carried out only with well-selected patients.

Question 12: In the case of isolated cells after sentinel lymph node dissection (SLND) followed by ALND, 20 centers (77\%) did not irradiate the ganglion areas. One center irradiated only the supraclavicular area, and two centers treated the internal mammary lymph node (IMN) and supraclavicular area.

The NORA survey reported comparable results. For the vast majority of respondents in both surveys, there was no indication to irradiate the node areas in this situation. The supraclavicular area, axillary area and IMN area were treated with $4 \%, 4 \%$, and $0 \%$, respectively (5). The French guidelines do not recommend systematic irradiation for tumors located in the external quadrants and in the case of isolated cells. In tumors located in the internal and central quadrants, the indication should be modulated "according to the tumor size, patient's age and associated comorbidities as well as consideration of the risk/benefit ratio" $(43,44)$. The National Comprehensive Cancer Network (NCCN) guidelines do not provide specific recommendations in the case of isolated cells [45].
Question 13: In the case of microscopic cells after SLND followed by ALND, 54\% of respondents did not irradiate any lymph node areas. Nineteen percent irradiated only the supraclavicular area. Eight percent of respondents irradiated the whole regional node area (IMN, supraclavicular and axillary areas).

In the NORA survey, $2 \%, 24 \%$ and $7 \%$ of the centers retained the indication for treatment of the IMN and the supraclavicular and axillary areas, respectively, in the same situation. We can note that irradiation of the IMN and the supraclavicular area is more frequent in our survey but less frequent for the axillary area in comparison with Belkacémi et al. [5]. In tumors located in the internal and central quadrants, the indication should be modulated "according to the tumor size, patient's age and associated comorbidities as well as consideration of the risk/benefit ratio" $[43,44]$. The National Comprehensive Cancer Network (NCCN) guidelines do not provide specific recommendations on appropriate conduct in the case of micrometastases [45].

Question 14: In cases of macroscopic disease after the SLND procedure followed by ALND, less than 5 out of 10 affected lymph nodes were found. All of the centers irradiated the supraclavicular area. The IMN was irradiated by $69 \%$ of the surveyed centers, and the axillary area was irradiated by $15 \%$ of them.

In a similar clinical situation, the indication of irradiation of each lymph node area was retained more in our investigation than in the previous study. In the study by Belkacémi et al., the number of affected lymph nodes and the number of lymph nodes sampled were not specified [5]. The NCCN recommends "irradiation of supraclavicular areas, IMN, and any part of the axillary bed that may be suspicious" [45]. The French recommendations systematically retain the irradiation of the supraclavicular and IMN areas in this situation. These guidelines recommend that the indication for axillary radiation therapy after ALND be discussed at the MTM. They retain the indication in cases of massive invasion (with consideration of the nodal ratio) [43].

Question 15: In the case of isolated cells in the SLND procedure, without ALND, 74\% of the centers did not irradiate any lymph node area, and $12 \%$ treated either the supraclavicular, IMN and axillary areas or only the supraclavicular area. 
The NORA survey found a comparable $14 \%$ of centers performing axillary area irradiation, but only $1.2 \%$ irradiated the IMN and $8 \%$ irradiated the supraclavicular area [5]. In the meta-analysis of Van Deurzen et al., which included 29 publications, the overall risk of macroscopic lymph node invasion in cases of SLND involvement by isolated cells was $12.3 \%$. The authors concluded that there was an indication for axillary dissection in the case of positive SLND with isolated cells if patients did not receive any adjuvant systemic therapy [46]. Two retrospective studies reported divergent results $[47,48]$. De Boer et al. showed a lower 5-year progression-free survival (PFS) in patients with axillary involvement by isolated cells [47], although Hansen et al. found no significant difference in 8-year PFS and OS for patients with SLND-isolated cells compared to those with SLND-negative cells [48]. The prospective NSABPB-32, IBCSG23-01 and ACOSOG Z0011 trials included breast cancer patients with isolated SLND cells. These trials were not performed to show a specific difference in this subpopulation, but the subgroup analysis did not show any benefit in OR or in recurrence-free survival (RFS) in the groups that received local axillary treatment [49-51].

Question 16: In the case of axillary microscopic involvement after the SLND procedure without ALND, $50 \%$ of the centers did not treat the lymph node areas; $15 \%$ treated the supraclavicular area; another $15 \%$ treated the supraclavicular, IMN and axillary areas; and $4 \%$ treated the supraclavicular and axillary areas.
The supraclavicular result compared favorably with those of the NORA survey with a value of $34 \%$ for supraclavicular and axillary irradiation. For IMN, only $5 \%$ of the centers retained the indication. The prospective IBCSG 23-01 and AATRM 048/13/2000 trials did not show any significant benefit in OS and RFS for patients with breast cancer and micrometastatic SLND who underwent local axillary irradiation $[49,52]$. The IMN irradiation indication is more important in our survey than in Belkacémi et al's results [5]. The indications for irradiation of the IMN are still debated [53-55]. Two trials demonstrated a RFS and specific survival benefit but no OS benefit after lymph node irradiation in cases of axillary lymph node invasion or high-risk node-positive breast cancer, but in these two trials, identifying the specific role of IMN irradiation on the benefit to other lymph node areas was not possible $[53,54]$. The debate also concerned the long-term impact of this irradiation and radiation-induced cardiac complications [56]. According to Hennequin et al., patients with axillary lymph node invasion with a central tumor with poor prognostic factors (triple negative, vascular invasion, SBR grade 3, young age) could benefit from IMN irradiation [57]. The authors described four predictive groups that benefit from IMN irradiation. The groups were based on histological findings, imaging and tumor location in the breast (Tab. 1) [44]. Recently, Jellesmark et al. analyzed a set of patients with and without IMN irradiation. The positive impact on OS appeared to be greater for patients with metastatic lymph node involvement [55]. If these groups according to Hennequin can represent a putative irradiation reference, the

Table 1. Internal mammary lymph node irradiation benefit prediction groups (adapted from [44])

\begin{tabular}{|c|c|c|}
\hline 1 & $\begin{array}{l}\text { Subgroup benefiting (with a high } \\
\text { probability) from the irradiation of the } \\
\text { internal mammary lymph node chain }\end{array}$ & $\begin{array}{l}\text { Proven disease (positive biopsy) or highly suspect [positron emission tomography (PET), } \\
\text { positive computerized tomography (CT)] } \\
\text { Significant axillary lymph node involvement ( } \geq 4 \text { affected lymph nodes), especially if the } \\
\text { tumor is central or internal with aggressive criteria (young woman, grade } 3 \text {, unexpressed } \\
\text { hormone receptors, etc.) }\end{array}$ \\
\hline 2 & $\begin{array}{l}\text { Subgroup whose benefit from irradiation } \\
\text { of the internal mammary node chain is } \\
\text { probable }\end{array}$ & Internal tumor with moderate axillary involvement (1-3 lymph nodes affected) \\
\hline 3 & $\begin{array}{l}\text { Subgroup whose benefit of irradiation } \\
\text { of the internal mammary node chain is } \\
\text { possible }\end{array}$ & $\begin{array}{l}\text { External tumor with moderate axillary involvement (1-3 lymph nodes affected) } \\
\text { Tumor of the internal quadrants pNO }\end{array}$ \\
\hline 4 & $\begin{array}{l}\text { Subgroup probably not benefiting from } \\
\text { irradiation of the internal mammary } \\
\text { node chain }\end{array}$ & External tumor and no histologically affected lymph node \\
\hline
\end{tabular}


final decision to irradiate IMN should be made in an MTM [57].

Concerning the cardiac risks calculated in the study by Hennequin et al. published in 2013, they appeared to be significant mainly in patients who had been treated more than 12 to 15 years previously and can currently be discussed because of the irradiation techniques now used [58]. Darby et al. showed in 2013 that cardiovascular risk began 5 years after radiotherapy and continued up to 30 years after irradiation, independent of the patient's own cardiovascular risks. The risk increased by approximately $7 \%$ per Gy above an average dose of approximately $5 \mathrm{~Gy}$ in the whole heart [56]. However, recent studies have highlighted the important role of the number of beams used [59] and the irradiation techniques used $[60,61]$. The systematic review of Drost et al. showed that breathing control significantly reduced the mean dose delivered to the heart. They also showed that the mean dose steadily decreased over the years (between 2014 and 2017) [61].

Question 17: In the case of pT2 tumors with macroscopic axillary involvement after the SLND procedure without ALND, none of the centers omitted lymph node irradiation. The supraclavicular, IMN and axillary areas were irradiated together by $42 \%$ of the centers; $12 \%$ of the centers irradiated the supraclavicular and axillary areas; $8 \%$ irradiated only the supraclavicular area; and 4\% irradiated the IMN and axillary areas.
The NORA survey showed a lower frequency of axillary irradiation for this same indication (57\%) [5]. Since the publication of the ACOSOG Z0011 trial in 2017 and AMAROS in 2015, the place of ALND and axillary irradiation has been questioned for patients with stage T1-T2 breast cancer $[4,51]$. The prospective ACOSOG Z0011 trial included 891 patients with $\mathrm{T} 1$ or T2 tumors with one or two nodes positive for the SLND procedure. All patients underwent partial mastectomy followed by WBI. With a median follow-up of 6.3 years, there was no difference in OS and LRS between patients with and without ALND. It should be noted that this study was the subject of several criticisms because the number of included patients was much lower than initially planned and the irradiation carried out was heterogeneous [51]. The prospective AMAROS trial, which included 1425 women with cancer classified as T1-2 with axillary invasion diagnosed after the SLND procedure, showed that it was equivalent to substituting complementary ALND with axillary irradiation. Indeed, the authors found no significant difference between the two groups in terms of axillary RFS, DFS and OS [4]. Table 3 summarizes the indications for lymph node irradiation according to French, European and American guidelines $[44,45,62]$ and the regional lymph node irradiation rates according to axillary involvement in our survey and the NORA survey (5) (Supplementary File - Tab. S1).

Table 2. Recommendations concerning axillary irradiation after ALND (adapted from [71])

\begin{tabular}{|c|c|}
\hline Reference & Recommendations \\
\hline Saint Paul de Vence, 2011 [43] & $\begin{array}{l}\text { Massive invasion of ALND with at least seven lymph nodes } \\
\text { In cases of insufficient ALND (less than seven lymph nodes) }\end{array}$ \\
\hline Remagus, 2019-2020 [88] & $\begin{array}{l}\text { Ratio of metastatic nodes to nodes }>50 \% \text { at ALND } \\
\text { In cases of insufficient ALND ( }<6 \text { nodes) } \\
\text { To be validated by MTM }\end{array}$ \\
\hline NHS MCCN, 2018 [89] & $\begin{array}{l}\text { Unspecified node involvement with }<4 \text { nodes on ALND } \\
\text { Metastatic lymph node with }<4 \text { nodes on ALND }\end{array}$ \\
\hline ASCO, $2001[90]$ & Not systematic; insufficient level of evidence to make a recommendation \\
\hline Saint-Gallen, 2013 [91] & Not systematic; no vote on the indications for axillary irradiation after ALND \\
\hline NCCN, 2020 [45] & Indication for unspecified axillary irradiation \\
\hline Inca, 2008 [92] & $\begin{array}{l}\text { After ALND to be discussed in MTM according to the number of lymph nodes examined, affected } \\
\text { and extranodal extension }\end{array}$ \\
\hline RECORAD, 2016 [44] & $\geq 10$ lymph nodes affected and/or removal of $<10$ lymph nodes but half or more affected \\
\hline
\end{tabular}


Question 18: Technically, axillary irradiation was carried out by enlarged tangential mammary beams, enlarged supraclavicular beams or specific beams in $4 \%, 13 \%$ and $22 \%$ of the centers, respectively. In this situation, $48 \%$ of the centers treated patients with IMRT.

Concerning the axillary area, Berg level I was generally included in the opposite tangential beams, but levels II and III have limited coverage by tangential beams despite the use of widened tangential beams [63-68] (CANRAD-D-19-00135R1). In 2004, Jephcott et al. showed that the addition of an anterior and posterior beam provided better coverage of the predicted target volume (PTV) but increased the areas of overdose above $120 \%$ of the prescribed dose [69]. In 2013, Hernandez et al. demonstrated a significant difference in coverage of axillary levels in favor of irradiation combining a modified anterior and posterior beam [70]. The axillary area irradiation technique was heterogeneous, as our investigation reports.

Question 19: The relevant criteria for axillary irradiation were that at least $50 \%$ of the lymph nodes were invaded in $74 \%$ of the centers. In terms of the number of removed lymph nodes in total, less than four, seven or ten were relevant criteria for $57 \%$, $13 \%$ and $4 \%$ of the centers, respectively. Other criteria were specified: the presence of capsular rupture, macroscopic remnants, involvement of $100 \%$ of the harvested nodes, invasion of fat and PET-CT data.

The indications for axillary irradiation are heterogeneous and vary according to the recommendations (Tab. 2). Rivera et al. retained the indication of axillary irradiation in cases of axillary lymph node involvement and incomplete ALND, massive axillary involvement and axillary fat invasion [71]. In 2016, Hennequin et al. identified unspecified massive axillary involvement and insufficient clearance defined by less than ten lymph nodes removed as criteria to irradiate the axillary area [44]. Axillary irradiation, because of the risk of side effects, should require validation in a MTM.

Question 20: Except in cases of trial inclusion, HF-RT was retained by $96 \%$ of the centers for WBI with or without boost and by $48 \%, 13 \%$ and $9 \%$ of the centers in cases of irradiation of the chest wall, breast and lymph node areas and chest wall and lymph node areas, respectively.
The survey by Van der Laan et al. described the use of HF-RT in only $28 \%$ of the surveyed centers. HF-RT was not performed in any of the four German centers, while four out of five UK centers prescribed 15-fraction treatment of $2.67 \mathrm{~Gy}$. This greater use of HF-RT in the UK is probably related to the publication of the START-B trial $[72,73]$. Another explanation could be the lower ease of access to radiotherapy facilities, the cost of treatment based on the number of fractions and the long distance to reach a radiotherapy center [74-77]. The survey by Ratosa et al. confirms the previous results. The use of HF-RT is heterogeneous on a European scale. HF-RT was chosen as the preferred schedule for WBI and for WBI and lymph node area irradiation by $54.7 \%$ and $28.7 \%$ of the responding radiation oncologists, respectively (78). Park et al. showed that $36 \%$ of the surveyed radiation oncologists used HF-RT, and among them, 26\% performed both breast and lymph node HF-RT [79]. Wang et al. published a randomized trial showing that postmastectomy hypofractionated radiotherapy, including regional node irradiation, is noninferior and has similar toxicities compared to conventionally fractionated radiotherapy; however, late toxicity data are insufficient to recommend HT-RT for all patients [80]. The results of the HYPOG01 (NCT03127995) trial will provide answers to late toxicity. The St. Gallen 2019 guidelines indicated that HF-RT can be used for most patients as a care standard (52\% for all patients and 19\% following breast conservation only) [81]. The Covid-19 pandemic was also an argument for the publication of recommendations on HF-RT in an effort to mitigate risk to patients and optimize resource utilization $[82,83]$. Coles et al. proposed in their guidelines HF-RT for all breast or chest wall and nodal irradiation in a moderately hypofractionated scheme [82]. Braunstein et al. published similar recommendations proposing hypofractionated radiotherapy for all breast or chest wall and nodal irradiation [83].

Question 21 and 22: In the context of adjuvant $H F-R T$, the total dose and fractionation retained by $74 \%$ of the centers was 40 Gy in 15 fractions. Specifically, 42.5 Gy in 16 fractions, 5 fractions per week, 41.6 Gy in 13 fractions, 5 fractions per week and 39 Gy in 13 fractions, 3 fractions per week were retained by $35 \%, 9 \%$ and $9 \%$ of the centers, respectively. Three centers used one of the three following schedules: 40.5 
Gy in 15 fractions of 2.7 Gy, 5 fractions per week, 45 Gy in 15 fractions, 3 fractions per week, and $28.5 \mathrm{~Gy}$ in 5 fractions, 1 fraction per week.

For the boost during HF-RT, the total dose and fractionation were $10 \mathrm{~Gy}$ in 4 fractions, $16 \mathrm{~Gy}$ in 8 fractions and 10 Gy in 5 fractions for 48\%, 26\% and $22 \%$ of the centers, respectively. The schedule with a total dose of 12.5 Gy in 5 fractions was retained by only one center. One center did not perform any hypofractionated boost outside therapeutic trials.

The dose and fractionation in the case of breast irradiation and boost are heterogeneous. This heterogeneity is also reported in several articles $[19,37,79]$. The most commonly used scheme is $40 \mathrm{~Gy}$ in 15 fractions according to the START$\mathrm{B}$ trial [73]. For the boost, the most commonly used scheme is the Lyon schedule delivering 10 Gy in 4 fractions [84]. Four phase III trials compared mammary HF-RT to normofractionated irradiation (50 Gy in 25 fractions) in terms of local control, side effects and cosmetic results. The trial by Yarnold et al. randomized 1410 patients with stage $\mathrm{T} 1-\mathrm{T} 3 / \mathrm{N} 0-\mathrm{N} 1$ breast cancer into three groups: 50 Gy in 25 fractions, 39 Gy in 13 fractions and 42.9 Gy in 13 fractions. In this study, $75 \%$ of the patients received a tumor bed boost of 14 Gy in 7 fractions by a direct electron beam [85]. The START A trial randomized 2236 pT1-3a pN0-1 patients into three groups: normofractionated (50 Gy/25 fractions) and hypofractionated (41.6 Gy/13 fractions and 39 Gy/13 fractions) irradiation. In this trial, $60.6 \%$ of patients received a boost with an electron beam at a dose of $10 \mathrm{~Gy}$ in 5 fractions (86). The START B trial included 2215 patients with the same criteria as the START A trial. It compared normofractionated irradiation (50 Gy/25 fractions) to HF-RT (40 Gy/15 fractions). Only $42.6 \%$ of patients received a boost, as in the START A trial, at a dose of 10 Gy in 5 fractions by a direct electron beam (73). The Canadian trial included 1234 randomized pT1-2 N0 patients in the standard arm (50 Gy/25 fractions) or in the experimental arm (42.5 Gy/16 fractions). There was no boost in this trial [87]. Consequently, it is difficult to conclude whether a hypofractionated boost should be used simultaneously or sequentially. However, from a financial point of view, in France, payment by the number of sessions and not by the treatment protocol as such cannot help to achieve the boost concomitantly.

\section{Conclusion}

This survey showed that French practices remained heterogeneous despite the publication of national and international references, particularly concerning irradiation techniques, prescribed doses and indications of irradiation of lymph node areas. This may be due to the different technology parks in the different centers but also to the more or less precise application of these guidelines. These results imply that there is a need to standardize practices with additional clinical studies being conducted, including radiation therapy for lymphatic drainage, to support existing guidelines. These studies should establish a more standardized treatment of lymph node regions in clinical practice. Finally, quality assurance should impose a broad application of consensus recommendations.

\section{Conflict of interest}

On behalf of all authors, the corresponding author states that there is no conflict of interest.

\section{Funding}

No funding source declared.

\section{Ethical approval statement}

All of the authors have approved the contents of this paper and have agreed to journal's ethical policies. All procedures performed in studies involving human participants were in accordance with the ethical standards of the institutional and/or national research committee and with the 1964 Helsinki declaration and its later amendments or comparable ethical standards.

\section{References}

1. Binder-Foucard F, Bossard N, Delafosse P, et al. French network of cancer registries (Francim). Cancer incidence and mortality in France over the 1980-2012 period: solid tumors. Rev Epidemiol Sante Publique. 2014; 62(2): 95-108, doi: 10.1016/j.respe.2013.11.073, indexed in Pubmed: 24613140.

2. Vaidya JS, Wenz F, Bulsara M, et al. TARGIT trialists' group. Risk-adapted targeted intraoperative radiotherapy versus whole-breast radiotherapy for breast cancer: 5-year results for local control and overall survival from the TARGIT-A randomised trial. Lancet. 2014; 383(9917): 603-613, doi: 10.1016/S0140-6736(13)61950-9, indexed in Pubmed: 24224997.

3. Veronesi U, Orecchia R, Maisonneuve P, et al. Intraoperative radiotherapy versus external radiotherapy for early breast 
cancer (ELIOT): a randomised controlled equivalence trial. Lancet Oncol. 2013; 14(13): 1269-1277, doi: 10.1016/ S1470-2045(13)70497-2, indexed in Pubmed: 24225155.

4. Donker M, Slaets L, van Tienhoven G, et al. Radiotherapy or surgery of the axilla after a positive sentinel node in breast cancer (EORTC 10981-22023 AMAROS): a randomised, multicentre, open-label, phase 3 non-inferiority trial. Lancet Oncol. 2014; 15(12): 1303-1310, doi: 10.1016/ S1470-2045(14)70460-7, indexed in Pubmed: 25439688.

5. Belkacemi Y, Kaidar-Person O, Poortmans P, et al. Breast Working Party of the EORTC Radiation Oncology Group (ROG). Patterns of practice of regional nodal irradiation in breast cancer: results of the European Organization for Research and Treatment of Cancer (EORTC) NOdal Radiotherapy (NORA) survey. Ann Oncol. 2015; 26(3): 529-535, doi: 10.1093/annonc/mdu561, indexed in Pubmed: 25480875.

6. Offersen BV, Boersma LJ, Kirkove C, et al. ESTRO consensus guideline on target volume delineation for elective radiation therapy of early stage breast cancer. Radiother Oncol. 2015; 114(1): 3-10, doi: 10.1016/j.radonc.2014.11.030, indexed in Pubmed: 25630428.

7. Smith BD, Bellon JR, Blitzblau R, et al. Radiation therapy for the whole breast: Executive summary of an American Society for Radiation Oncology (ASTRO) evidence-based guideline. Pract Radiat Oncol. 2018; 8(3): 145-152, doi: 10.1016/j.prro.2018.01.012, indexed in Pubmed: 29545124.

8. Podgorsak EB, Gosselin M, Kim TH, et al. A simple isocentric technique for irradiation of the breast, chest wall and peripheral lymphatics. Br J Radiol. 1984; 57(673): 57-63, doi: 10.1259/0007-1285-57-673-57, indexed in Pubmed: 6423026.

9. Kagkiouzis J, Platoni K, Kantzou I, et al. Review of the threefield techniques in breast cancer radiotherapy. J BUON. 2017; 22(3): 599-605, indexed in Pubmed: 28730762.

10. Banaei A, Hashemi B, Bakhshandeh M. Comparing the monoisocentric and dual isocentric techniques in chest wall radiotherapy of mastectomy patients. J Appl Clin Med Phys. 2015; 16(1): 5069, doi: 10.1120/jacmp.v16i1.5069, indexed in Pubmed: 25679164.

11. Toulba A AF, Lkhouyaali S NM. Mono-Isocentric Technique in the Breast Cancer and Organ at Risk Tolerance. J Nucl Med Radiat Ther [Internet]. 2013. https://www.omicsonline.org/mono-isocentric-technique-in-the-breastcancer-and-organ-at-risk-tolerance-2155-9619.S2-010. php?aid=9169 (29 Nov 2019).

12. Zhang T, Dilworth JT, Marina O, et al. A three-field monoisocentric inverse breast treatment planning technique without half-beam blocking. J Appl Clin Med Phys. 2015; 16(5): 246-258, doi: 10.1120/jacmp.v16i5.5494, indexed in Pubmed: 26699305.

13. Gez E, Assaf N, Ashaf N, et al. Postmastectomy electronbeam chest-wall irradiation in women with breast cancer. Int J Radiat Oncol Biol Phys. 2004; 60(4): 11901194, doi: 10.1016/j.ijrobp.2004.05.036, indexed in Pubmed: 15519791.

14. Grellier Adedjouma N, Chevrier M, Fourquet A, et al. Long-Term Results of a Highly Performing Conformal Electron Therapy Technique for Chest Wall Irradiation After Mastectomy. Int J Radiat Oncol Biol Phys. 2017; 98(1): 206-214, doi: 10.1016/j.ijrobp.2017.01.205, indexed in Pubmed: 28586961.
15. Kirova YM, Campana F, Fournier-Bidoz N, et al. Postmastectomy electron beam chest wall irradiation in women with breast cancer: a clinical step toward conformal electron therapy. Int J Radiat Oncol Biol Phys. 2007; 69(4): 1139-1144, doi: 10.1016/j.ijrobp.2007.05.007, indexed in Pubmed: 17689024.

16. Feigenberg SJ, Price Mendenhall N, Benda RK, et al. Postmastectomy radiotherapy: patterns of recurrence and long-term disease control using electrons. Int J Radiat Oncol Biol Phys. 2003; 56(3): 716-725, doi: 10.1016/ s0360-3016(03)00112-3, indexed in Pubmed: 12788177.

17. Jackson SM. The clinical application of electron beam therapy with energies up to $10 \mathrm{MeV}$. Br J Radiol. 1970; 43(511): 431-440, doi: 10.1259/0007-1285-43-511-431, indexed in Pubmed: 5429078.

18. Smith BD, Pan IW, Shih YCT, et al. Adoption of intensitymodulated radiation therapy for breast cancer in the United States. J Natl Cancer Inst. 2011; 103(10): 798-809, doi: 10.1093/jnci/djr100, indexed in Pubmed: 21525437.

19. van der Laan HP, Dolsma WV, van't Veld AA, et al. Comparison of normal tissue dose with three-dimensional conformal techniques for breast cancer irradiation including the internal mammary nodes. Int J Radiat Oncol Biol Phys. 2005; 63(5): 1522-1530, doi: 10.1016/j.jijrobp.2005.04.027, indexed in Pubmed: 15994027.

20. Bourgier C, Aimard L, Bodez V, et al. Adjuvant radiotherapy in the management of axillary node negative invasive breast cancer: a qualitative systematic review. Crit Rev Oncol Hematol. 2013; 86(1): 33-41, doi: 10.1016/j.critrevonc.2012.09.010, indexed in Pubmed: 23088955.

21. Liu H, Chen X, He Z, et al. Evaluation of 3D-CRT, IMRT and VMAT radiotherapy plans for left breast cancer based on clinical dosimetric study. Comput Med Imaging Graph. 2016; 54: 1-5, doi: 10.1016/j.compmedimag.2016.10.001, indexed in Pubmed: 27838084.

22. Rastogi K, Sharma S, Gupta S, et al. Dosimetric comparison of IMRT versus 3DCRT for post-mastectomy chest wall irradiation. Radiat Oncol J. 2018; 36(1): 71-78, doi: 10.3857/ roj.2017.00381, indexed in Pubmed: 29621872.

23. Hong L, Hunt M, Chui C, et al. Intensity-modulated tangential beam irradiation of the intact breast. Int J Radiat Oncol Biol Phys. 1999; 44(5): 1155-1164, doi: 10.1016/ s0360-3016(99)00132-7, indexed in Pubmed: 10421550.

24. Lisbona A, Averbeck D, Supiot $S$, et al. Radiothérapie conformationnelle avec modulation d'intensité (RCMI) guidée par l'image : impact de l'augmentation du volume irradié à faible dose ? Cancer/Radiothérapie. 2010; 14(6-7): 563-570, doi: 10.1016/j.canrad.2010.07.227.

25. Fenoglietto. Impact de la modulation d'intensité dans l'irradiation des aires ganglionnaires du cancer du sein. 2015. https://app.dimensions.ai/details/publication/ pub.1026824672 (5 Déc 2019).

26. Hall E, Wuu CS. Radiation-induced second cancers: the impact of 3D-CRT and IMRT. Int J Radiat Oncol Biol Phys. 2003; 56(1): 83-88, doi: 10.1016/s0360-3016(03)00073-7, indexed in Pubmed: 12694826.

27. Purdy JA. Dose to normal tissues outside the radiation therapy patient's treated volume: a review of different radiation therapy techniques. Health Phys. 2008; 95(5): 666-676, doi: 10.1097/01.HP.0000326342.47348.06, indexed in Pubmed: 18849701.

28. Xu XG, Bednarz B, Paganetti H. A review of dosimetry studies on external-beam radiation treatment with respect 
to second cancer induction. Phys Med Biol. 2008; 53(13): R193-R241, doi: 10.1088/0031-9155/53/13/R01, indexed in Pubmed: 18540047.

29. Bartelink H, Horiot JC, Poortmans PM, et al. Impact of a higher radiation dose on local control and survival in breast-conserving therapy of early breast cancer: 10year results of the randomized boost versus no boost EORTC 22881-10882 trial. J Clin Oncol. 2007; 25(22): 3259-3265, doi: 10.1200/JCO.2007.11.4991, indexed in Pubmed: 17577015.

30. Vrieling C, van Werkhoven E, Maingon P, et al. European Organisation for Research and Treatment of Cancer, Radiation Oncology and Breast Cancer Groups. Prognostic Factors for Local Control in Breast Cancer After Long-term Follow-up in the EORTC Boost vs No Boost Trial: A Randomized Clinical Trial. JAMA Oncol. 2017; 3(1): 42-48, doi: 10.1001/jamaoncol.2016.3031, indexed in Pubmed: 27607734.

31. Kindts I, Verhoeven K, Laenen A, et al. A comparison of a brachytherapy and an external beam radiotherapy boost in breast-conserving therapy for breast cancer: local and any recurrences. Strahlenther Onkol. 2019; 195(4): 310-317, doi: 10.1007/s00066-018-1413-0, indexed in Pubmed: 30603857.

32. Vass S, Bairati I. A cosmetic evaluation of breast cancer treatment: a randomized study of radiotherapy boost technique. Int J Radiat Oncol Biol Phys. 2005; 62(5): 1274-1282, doi: 10.1016/j.jijrobp.2004.12.039, indexed in Pubmed: 16029782.

33. Renoult F, Marchal C, Brunaud C, et al. [Safety and efficacy of whole breast irradiation with a concomitant boost: analysis of 121 cases treated at the Institute of Cancerology of Lorraine]. Cancer Radiother. 2014; 18(3): 165-170, doi: 10.1016/j.canrad.2014.02.004, indexed in Pubmed: 24679650.

34. Guerrero M, Li XA, Earl MA, et al. Simultaneous integrated boost for breast cancer using IMRT: a radiobiological and treatment planning study. Int J Radiat Oncol Biol Phys. 2004; 59(5): 1513-1522, doi: 10.1016/j.ijrobp.2004.04.007, indexed in Pubmed: 15275739.

35. Van Parijs H, Miedema G, Vinh-Hung V, et al. Short course radiotherapy with simultaneous integrated boost for stage I-II breast cancer, early toxicities of a randomized clinical trial. Radiat Oncol. 2012; 7: 80, doi: 10.1186/1748717X-7-80, indexed in Pubmed: 22656865.

36. Lee $\mathrm{HH}$, Chen $\mathrm{CH}$, Luo $\mathrm{KH}$, et al. Five-year survival outcomes of intensity-modulated radiotherapy with simultaneous integrated boost (IMRT-SIB) using forward IMRT or Tomotherapy for breast cancer. Sci Rep. 2020; 10(1): 4342, doi: 10.1038/s41598-020-61403-6, indexed in Pubmed: 32152428.

37. Dundas KL, Pogson EM, Batumalai V, et al. Australian survey on current practices for breast radiotherapy. J Med Imaging Radiat Oncol. 2015; 59(6): 736-742, doi: 10.1111/17549485.12348, indexed in Pubmed: 26269376.

38. Sanders ME, Scroggins T, Ampil FL, et al. Accelerated partial breast irradiation in early-stage breast cancer. J Clin Oncol. 2007; 25(8): 996-1002, doi: 10.1200/JCO.2006.09.7436, indexed in Pubmed: 17350949.

39. Livi L, Meattini I, Marrazzo L, et al. Accelerated partial breast irradiation using intensity-modulated radiotherapy versus whole breast irradiation: 5-year survival analysis of a phase 3 randomised controlled trial. Eur J Cancer. 2015;
51(4): 451-463, doi: 10.1016/j.ejca.2014.12.013, indexed in Pubmed: 25605582.

40. Coles CE, Griffin CL, Kirby AM, et al. IMPORTTrialists. Partialbreast radiotherapy after breast conservation surgery for patients with early breast cancer (UK IMPORT LOW trial): 5-year results from a multicentre, randomised, controlled, phase 3, non-inferiority trial. Lancet. 2017; 390(10099): 1048-1060, doi: 10.1016/S0140-6736(17)31145-5, indexed in Pubmed: 28779963.

41. Senkus E, Kyriakides S, Ohno S, et al. ESMO Guidelines Committee. Primary breast cancer: ESMO Clinical Practice Guidelines for diagnosis, treatment and follow-up. Ann Oncol. 2015; 26 Suppl 5: v8-30, doi: 10.1093/annonc/ mdv298, indexed in Pubmed: 26314782.

42. Strnad V, Hannoun-Levi JM, Guinot JL, et al. Working Group Breast Cancer of GEC-ESTRO. Recommendations from GEC ESTRO Breast Cancer Working Group (I): Target definition and target delineation for accelerated or boost Partial Breast Irradiation using multicatheter interstitial brachytherapy after breast conserving closed cavity surgery. Radiother Oncol. 2015; 115(3): 342-348, doi: 10.1016/j. radonc.2015.06.010, indexed in Pubmed: 26104975.

43. Belkacémi Y, Fourquet $A$, Cutuli B, et al. French Expert Review Board of Nice/Saint-Paul de Vence. Radiotherapy for invasive breast cancer: guidelines for clinical practice from the French expert review board of Nice/SaintPaul de Vence. Crit Rev Oncol Hematol. 2011; 79(2): 91-102, doi: 10.1016/j.critrevonc.2010.06.002, indexed in Pubmed: 20615725.

44. Hennequin C, Barillot I, Azria D, et al. [Radiotherapy of breast cancer]. Cancer Radiother. 2016; 20(Suppl): S139-S146, doi: 10.1016/j.canrad.2016.07.025, indexed in Pubmed: 27522187.

45. Gradishar WJ, Anderson BO, Abraham J, et al. Breast Cancer, Version 3.2020, NCCN Clinical Practice Guidelines in Oncology. J Natl Compr Canc Netw. 2020; 18(4): 452-478, doi: 10.6004/jnccn.2020.0016, indexed in Pubmed: 32259783.

46. van Deurzen CHM, de Boer M, Monninkhof EM, et al. Non-sentinel lymph node metastases associated with isolated breast cancer cells in the sentinel node. J Natl Cancer Inst. 2008; 100(22): 1574-1580, doi: 10.1093/jnci/ djn343, indexed in Pubmed: 19001602.

47. de Boer M, van Deurzen CHM, van Dijck JA, et al. Micrometastases or isolated tumor cells and the outcome of breast cancer. N Engl J Med. 2009; 361 (7): 653-663, doi: 10.1056/ NEJMoa0904832, indexed in Pubmed: 19675329.

48. Hansen NM, Grube B, Ye X, et al. Impact of micrometastases in the sentinel node of patients with invasive breast cancer. J Clin Oncol. 2009; 27(28): 4679-4684, doi: 10.1200/ JCO.2008.19.0686, indexed in Pubmed: 19720928.

49. Galimberti V, Cole BF, Viale G, et al. International Breast Cancer Study Group Trial 23-01, International Breast Cancer Study Group Trial 23-01 investigators. Axillary dissection versus no axillary dissection in patients with sentinel-node micrometastases (IBCSG 23-01): a phase 3 randomised controlled trial. Lancet Oncol. 2013; 14(4): 297-305, doi: 10.1016/S1470-2045(13)70035-4, indexed in Pubmed: 23491275.

50. Krag DN, Anderson SJ, Julian TB, et al. Sentinel-lymphnode resection compared with conventional axillarylymph-node dissection in clinically node-negative patients with breast cancer: overall survival findings from the 
NSABP B-32 randomised phase 3 trial. Lancet Oncol. 2010; 11(10): 927-933, doi: 10.1016/S1470-2045(10)70207-2, indexed in Pubmed: 20863759.

51. Giuliano AE, Ballman KV, McCall L, et al. Effect of Axillary Dissection vs No Axillary Dissection on 10-Year Overall Survival Among Women With Invasive Breast Cancer and Sentinel Node Metastasis: The ACOSOG Z0011 (Alliance) Randomized Clinical Trial. JAMA. 2017; 318(10): 918-926, doi: 10.1001/jama.2017.11470, indexed in Pubmed: 28898379.

52. Solá M, Alberro JA, Fraile M, et al. Complete axillary lymph node dissection versus clinical follow-up in breast cancer patients with sentinel node micrometastasis: final results from the multicenter clinical trial AATRM 048/13/2000. Ann Surg Oncol. 2013; 20(1): 120-127, doi: 10.1245/ s10434-012-2569-y, indexed in Pubmed: 22956062.

53. Poortmans $P$, Weltens C, Fortpied C, et al. Internal mammary and medial supraclavicular lymph node chain irradiation in stage I-III breast cancer (EORTC 22922/10925): 15 -year results of a randomised, phase 3 trial. Lancet Oncol. 2020; 21(12): 1602-1610, doi: 10.1016/s14702045(20)30472-1, indexed in Pubmed: 33152277.

54. Whelan TJ, Olivotto IA, Parulekar WR, et al. MA.20 Study Investigators. Regional Nodal Irradiation in Early-Stage Breast Cancer. N Engl J Med. 2015; 373(4): 307-316, doi: 10.1056/NEJMoa1415340, indexed in Pubmed: 26200977.

55. Thorsen LB, Offersen BV, Danø H, et al. DBCG-IMN: A Population-Based Cohort Study on the Effect of Internal Mammary Node Irradiation in Early Node-Positive Breast Cancer. J Clin Oncol. 2016; 34(4): 314-320, doi: 10.1200/ JCO.2015.63.6456, indexed in Pubmed: 26598752.

56. Darby SC, Ewertz M, McGale P, et al. Risk of ischemic heart disease in women after radiotherapy for breast cancer. N Engl J Med. 2013; 368(11): 987-998, doi: 10.1056/NEJMoa1209825, indexed in Pubmed: 23484825.

57. Hennequin C, Fourquet $A$. [Controversy about internal mammary chain irradiation in breast cancer]. Cancer Radiother. 2014; 18(5-6): 351-355, doi: 10.1016/j.canrad.2014.06.016, indexed in Pubmed: 25169067.

58. Hennequin C, Bossard N, Servagi-Vernat S, et al. Ten-year survival results of a randomized trial of irradiation of internal mammary nodes after mastectomy. Int J Radiat Oncol Biol Phys. 2013; 86(5): 860-866, doi: 10.1016/j. ijrobp.2013.03.021, indexed in Pubmed: 23664327.

59. Rahimy E, Hong JC, Gross CP, et al. Increased Number of Beam Angles Is Associated With Higher Cardiac Dose in Adjuvant Fixed Gantry Intensity Modulated Radiation Therapy of Left-Sided Breast Cancer. Int J Radiat Oncol Biol Phys. 2017; 99(5): 1137-1145, doi: 10.1016/j. ijrobp.2017.06.2451, indexed in Pubmed: 28864402.

60. Dess RT, Liss AL, Griffith KA, et al. Ischemic Cardiac Events Following Treatment of the Internal Mammary Nodal Region Using Contemporary Radiation Planning Techniques. Int J Radiat Oncol Biol Phys. 2017; 99(5): 1146-1153, doi: 10.1016/j.jjrobp.2017.06.2459, indexed in Pubmed: 28864405.

61. Drost L, Yee C, Lam H, et al. A Systematic Review of Heart Dose in Breast Radiotherapy. Clin Breast Cancer. 2018; 18(5): e819-e824, doi: 10.1016/j.clbc.2018.05.010, indexed in Pubmed: 29980429.

62. Cardoso F, Kyriakides S, Ohno S, et al. ESMO Guidelines Committee. Early breast cancer: ESMO Clinical Practice
Guidelines for diagnosis, treatment and follow-up. Ann Oncol. 2019; 30(10): 1674, doi: 10.1093/annonc/mdz189, indexed in Pubmed: 31236598.

63. Krasin M, McCall A, King S, et al. Evaluation of a standard breast tangent technique: a dose-volume analysis of tangential irradiation using three-dimensional tools. Int J Radiat Oncol Biol Phys. 2000; 47(2): 327-333, doi: 10.1016/ s0360-3016(00)00449-1, indexed in Pubmed: 10802356.

64. Aristei C, Chionne F, Marsella A, et al. Evaluation of level I and II axillary nodes included in the standard breast tangential fields and calculation of the administered dose: results of a prospective study. Int J Radiat Oncol Biol Phys. 2001;51(1): 69-73, doi: 10.1016/s0360-3016(01)01595-4, indexed in Pubmed: 11516853.

65. Alço G, Iğdem SI, Ercan T, et al. Coverage of axillary lymph nodes with high tangential fields in breast radiotherapy. Br J Radiol. 2010; 83(996): 1072-1076, doi: 10.1259/ bjr/25788274, indexed in Pubmed: 21088091.

66. Orecchia R, Huscher A, Leonardi MC, et al. Irradiation with standard tangential breast fields in patients treated with conservative surgery and sentinel node biopsy: using a three-dimensional tool to evaluate the first level coverage of the axillary nodes. Br J Radiol. 2005; 78(925): 51-54, doi: 10.1259/bjr/29242407, indexed in Pubmed: 15673530.

67. Reed DR, Lindsley SK, Mann GN, et al. Axillary lymph node dose with tangential breast irradiation. Int J Radiat Oncol Biol Phys. 2005; 61(2): 358-364, doi: 10.1016/j. ijrobp.2004.06.006, indexed in Pubmed: 15667953.

68. Reznik J, Cicchetti MG, Degaspe B, et al. Analysis of axillary coverage during tangential radiation therapy to the breast. Int J Radiat Oncol Biol Phys. 2005; 61(1): 163-168, doi: 10.1016/j.ijrobp.2004.04.065, indexed in Pubmed: 15629607.

69. Jephcott CR, Tyldesley S, Swift CL. Regional radiotherapy to axilla and supraclavicular fossa for adjuvant breast treatment: a comparison of four techniques. Int J Radiat Oncol Biol Phys. 2004; 60(1): 103-110, doi: 10.1016/j. ijrobp.2004.02.057, indexed in Pubmed: 15337545.

70. Hernandez V, Arenas M, Müller K, et al. An optimized posterior axillary boost technique in radiation therapy to supraclavicular and axillary lymph nodes: a comparative study. Med Dosim. 2013; 38(4): 413-417, doi: 10.1016/j. meddos.2013.05.003, indexed in Pubmed: 23910694.

71. Rivera S, Louvel G, Campo ER, et al. Radiothérapie axillaire prophylactique des cancers du sein. Cancer/ Radiothérapie. 2015; 19(4): 253-260, doi: 10.1016/j.canrad.2015.05.001, indexed in Pubmed: 26044178.

72. van der Laan HP, Hurkmans CW, Kuten A, et al. EORTCROG Breast Working Party. Current technological clinical practice in breast radiotherapy; results of a survey in EORTC-Radiation Oncology Group affiliated institutions. Radiother Oncol. 2010; 94(3): 280-285, doi: 10.1016/j. radonc.2009.12.032, indexed in Pubmed: 20116120.

73. Haviland JS, Owen JR, Dewar JA, et al. START Trialists' Group, START Trialists' Group, START Trialists' Group. The UK Standardisation of Breast Radiotherapy (START) Trial B of radiotherapy hypofractionation for treatment of early breast cancer: a randomised trial. Lancet. 2008; 371(9618): 1098-1107, doi: 10.1016/S0140-6736(08)60348-7, indexed in Pubmed: 18355913.

74. Nattinger AB, Gottlieb MS, Veum J, et al. Geographic variation in the use of breast-conserving treatment for 
breast cancer. N Engl J Med. 1992; 326(17): 1102-1107, doi: 10.1056/NEJM199204233261702, indexed in Pubmed: 1552911.

75. Farrow DC, Hunt WC, Samet JM. Geographic variation in the treatment of localized breast cancer. $\mathrm{N}$ Engl J Med. 1992; 326(17): 1097-1101, doi: 10.1056/ NEJM199204233261701, indexed in Pubmed: 1552910.

76. Lazovich DA, White E, Thomas DB, et al. Underutilization of breast-conserving surgery and radiation therapy among women with stage I or II breast cancer. JAMA. 1991; 266(24): 3433-3438, indexed in Pubmed: 1688350.

77. Zubizarreta E, Van Dyk J, Lievens Y. Analysis of Global Radiotherapy Needs and Costs by Geographic Region and Income Level. Clin Oncol (R Coll Radiol). 2017; 29(2): 84-92, doi: 10.1016/j.clon.2016.11.011, indexed in Pubmed: 27939337.

78. Ratosa I, Chirilă ME, Steinacher M, et al. Hypofractionated radiation therapy for breast cancer: Preferences amongst radiation oncologists in Europe - Results from an international survey. Radiother Oncol. 2021; 155: 17-26, doi: 10.1016/j.radonc.2020.10.008, indexed in Pubmed: 33065187.

79. Park HJ, Oh DoH, Shin KH, et al. Division for Breast Cancer, Korean Radiation Oncology Group. Patterns of Practice in Radiotherapy for Breast Cancer in Korea. J Breast Cancer. 2018; 21(3): 244-250, doi: 10.4048/jbc.2018.21.e37, indexed in Pubmed: 30275852.

80. Wang SL, Fang $\mathrm{H}$, Song YW, et al. Hypofractionated versus conventional fractionated postmastectomy radiotherapy for patients with high-risk breast cancer: a randomised, non-inferiority, open-label, phase 3 trial. Lancet Oncol. 2019; 20(3): 352-360, doi: 10.1016/s1470-2045(18)308131, indexed in Pubmed: 30711522.

81. Balic M, Thomssen C, Würstlein R, et al. St. Gallen/Vienna 2019: A Brief Summary of the Consensus Discussion on the Optimal Primary Breast Cancer Treatment. Breast Care (Basel). 2019; 14(2): 103-110, doi: 10.1159/000499931, indexed in Pubmed: 31798382.

82. Coles CE, Aristei C, Bliss J, et al. International Guidelines on Radiation Therapy for Breast Cancer During the COVID-19 Pandemic. Clin Oncol (R Coll Radiol). 2020; 32(5): 279-281, doi: 10.1016/j.clon.2020.03.006, indexed in Pubmed: 32241520.

83. Braunstein LZ, Gillespie EF, Hong L, et al. Breast Radiation Therapy Under COVID-19 Pandemic Resource Constraints-Approaches to Defer or Shorten Treatment From a Comprehensive Cancer Center in the United States. Adv Radiat Oncol. 2020; 5(4): 582-588, doi: 10.1016/j. adro.2020.03.013, indexed in Pubmed: 32292842.
84. Romestaing $P$, Lehingue $Y$, Carrie $C$, et al. Role of a 10Gy boost in the conservative treatment of early breast cancer: results of a randomized clinical trial in Lyon, France. J Clin Oncol. 1997; 15(3): 963-968, doi: 10.1200/ JCO.1997.15.3.963, indexed in Pubmed: 9060534.

85. Yarnold J, Ashton A, Bliss J, et al. Fractionation sensitivity and dose response of late adverse effects in the breast after radiotherapy for early breast cancer: long-term results of a randomised trial. Radiother Oncol. 2005; 75(1): 9-17, doi: 10.1016/j.radonc.2005.01.005, indexed in Pubmed: 15878095.

86. Bentzen SM, Agrawal RK, Aird EG, et al. START Trialists' Group. The UK Standardisation of Breast Radiotherapy (START) Trial A of radiotherapy hypofractionation for treatment of early breast cancer: a randomised trial. Lancet Oncol. 2008; 9(4): 331-341, doi: 10.1016/s14702045(08)70077-9.

87. Whelan TJ, Pignol JP, Levine MN, et al. Long-term results of hypofractionated radiation therapy for breast cancer. N Engl J Med. 2010; 362(6): 513-520, doi: 10.1056/NEJMoa0906260, indexed in Pubmed: 20147717.

88. Cottu P. et al. Attitudes diagnostiques et thérapeutiques, protocoles de traitement 2019-2020 [Internet]. https:// www.gustaveroussy.fr/sites/default/files/referentielremagus-cancer-du-sein-gustave-roussy-institut-curie-2019-2021.pdf.

89. Robson et al. Guidelines for radiotherapy in early breast cancer. Merseyside and cheshire cancer network, warrington (2010) [Internet]. https://www.cmcanceralliance. nhs.uk/application/files/2815/4815/5651/CNG_Guidelines_for_Radiotherapy_in_Early_Breast_Cancer_ April_17.doc (19 Nov 2020).

90. Recht A, Edge SB, Solin LJ, et al. American Society of Clinical Oncology. Postmastectomy radiotherapy: clinical practice guidelines of the American Society of Clinical Oncology. J Clin Oncol. 2001; 19(5): 1539-1569, doi: 10.1200/JCO.2001.19.5.1539, indexed in Pubmed: 11230499.

91. Goldhirsch A, Winer EP, Coates AS, et al. Panel members. Personalizing the treatment of women with early breast cancer: highlights of the St Gallen International Expert Consensus on the Primary Therapy of Early Breast Cancer 2013. Ann Oncol. 2013; 24(9): 2206-2223, doi: 10.1093/ annonc/mdt303, indexed in Pubmed: 23917950.

92. Cancers du sein - Recommandations et outils d'aide à la pratique [Internet]. https://www.e-cancer.fr/Professionnels-de-sante/Recommandations-et-outils-d-aidea-la-pratique/Cancers-du-sein\#toc-recommandationsde-prise-en-charge-sp-cialis-e (19 Nov 2020). 